\section{Sonographic features that can be used to differentiate between small triple-negative breast cancer and fibroadenoma}

\author{
Ga Young Yoon, Joo Hee Cha, Hak Hee Kim, Hee Jung Shin, Eun Young Chae, \\ Woo Jung Choi
}

Department of Radiology and Research Institute of Radiology, Asan Medical Center, University of Ulsan College of Medicine, Seoul, Korea

Purpose: Our study investigated whether any sonographic findings could be useful for differentiating between small triple-negative breast cancer (TNBC) and fibroadenoma.

Methods: This retrospective study was approved by our Institutional Review Board, which waived the requirement for patient consent. From January 2009 to December 2010, the sonographic features of 181 pathologically proven TNBC tumors and 172 fibroadenomas measuring less than or equal to $2 \mathrm{~cm}$ in the longest dimension were reviewed and analyzed according to the fifth edition of the Breast Imaging Reporting and Data System (BI-RADS) lexicon. Mean tumor roundness was also measured using in-house software.

Results: The median longest lesion dimension was $16 \mathrm{~mm}$ (range, 13 to $18 \mathrm{~mm}$ ) in TNBCs and $13 \mathrm{~mm}$ (range, 10 to $16 \mathrm{~mm}$ ) in fibroadenomas. In comparison to fibroadenomas, small TNBC tumors presented with a higher incidence of irregular shapes $(66.9 \%)$, noncircumscribed margins (91.7\%), hypoechoic echotexture (59.1\%), posterior acoustic enhancement $(65.2 \%)$, and associated features (24.4\%). Most TNBCs were classified as BI-RADS category $4(65.2 \%)$ or $5(28.2 \%)$. The mean tumor roundness of small TNBCs was greater than that of fibroadenomas $(60 \% \pm 12 \%$ vs. $53 \% \pm 13 \%)$. Multivariate analysis showed that older patient age, irregular shape, nonparallel orientation, posterior acoustic enhancement, associated features, a BI-RADS final assessment category of 4 or 5 , and greater tumor roundness were significant independent factors indicative of TNBCs.

Conclusion: TNBC tumors tend to demonstrate more suspicious sonographic features and greater tumor roundness than fibroadenomas. These features may have the potential to help differentiate between small TNBCs and fibroadenomas.

Keywords: Triple negative breast neoplasms; Fibroadenoma; Ultrasonography

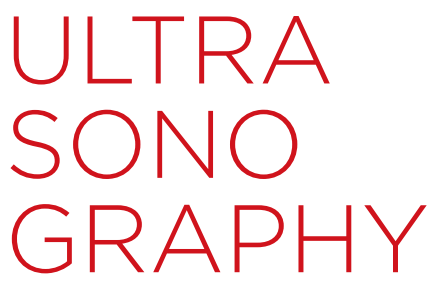

ORIGINAL ARTICLE

https://doi.org/10.14366/usg. 17036 pISSN: 2288-5919 • elSSN: 2288-5943 Ultrasonography 2018;37:149-156

Received: May 8, 2017

Revised: August 3, 2017

Accepted: August 4, 2017

Correspondence to: Joo Hee Cha, MD, Department of Radiology and Research Institute of Radiology, Asan Medical Center, University of Ulsan College of Medicine, 88 Olympic-ro 43-gil, Songpa-gu, Seoul 05505, Korea

Tel. +82-2-3010-5995

Fax. +82-2-476-0090

E-mail: jhcha@amc.seoul.kr

This is an Open Access article distributed under the terms of the Creative Commons Attribution NonCommercial License (http://creativecommons.org/ licenses/by-nc/3.0/) which permits unrestricted noncommercial use, distribution, and reproduction in any medium, provided the original work is properly cited.

Copyright (C) 2018 Korean Society of Ultrasound in Medicine (KSUM)

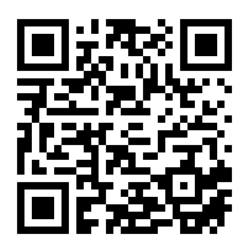

How to cite this article:

Yoon GY, Cha JH, Kim HH, Shin HJ, Chae EY, Choi WJ. Sonographic features that can be used to differentiate between small triplenegative breast cancer and fibroadenoma. Ultrasonography. 2018 Apr;37(2):149-156. 


\section{Introduction}

Triple-negative breast cancer (TNBC) is defined as a tumor that does not express estrogen receptor (ER), progesterone receptor (PR), or human epidermal growth factor receptor 2 (HER2) [1]. As TNBCs more commonly show noncalcification on imaging than other immunotypes and more common in younger women who have a family history of breast cancer or carry a BRCA1 or BRCA2 gene mutation, the mammographic diagnostic accuracy for TNBCs is relatively low $[2,3]$. Up to $18 \%$ of TNBCs are occult on initial mammography [4-6]. Screening using ultrasonography (US) may therefore provide additional benefits for identifying the TNBC subtype in high-risk women [7].

Dogan and Turnbull reviewed the multimodal imaging features of TNBC and reported that the imaging features of TNBC showed generally benign morphological characteristics on US [3], with a well-circumscribed margin and posterior acoustic enhancement, features that are common in benign neoplasms such as fibroadenomas $[6,8]$. Although it may have imaging features typical of benign neoplasms, this phenotype of breast cancer has a more aggressive clinical course than other forms of breast cancer, and is associated with aggressive histology and a poor outcome $[9,10]$. Misdiagnosis of this malignant tumor as a benign tumor may delay the treatment of TNBC and lead to a poor prognosis $[10,11]$.

In this study, we investigated whether sonographic findings could be used to differentiate between small TNBC and fibroadenoma.

\section{Materials and Methods}

\section{Patients}

This retrospective study was approved by the Istitutional Review Board of our hospital, and the requirement for informed consent from the patients was waived.

From January 2009 to December 2010, 3311 women underwent a breast-conserving operation or mastectomy in our hospital due to breast cancer. Seventy-nine patients with a history of breast cancer and six patients with occult breast cancer were initially excluded. Of the remaining patients, 558 were diagnosed with TNBC. After the exclusion of eight patients with an unknown tumor size because the excision had been performed at an outside hospital, 310 patients with a tumor larger than $2 \mathrm{~cm}, 54$ patients with calcification within a tumor on mammography, and five patients with a diffuse extensive intraductal component on the pathologic specimen, a total of 181 patients who were diagnosed with TNBC measuring less than or equal to $2 \mathrm{~cm}$ in the longest dimension, corresponding to the T1 stage, were included in this study (Fig. 1).

We also reviewed the consecutive cases of US-guided core needle biopsy within the same period, and 172 cases confirmed as fibroadenoma measuring less than or equal to $2 \mathrm{~cm}$ in the longest dimension were included in the study.

\section{US Examination and Imaging Review}

Sonography was performed in all patients using high-resolution US

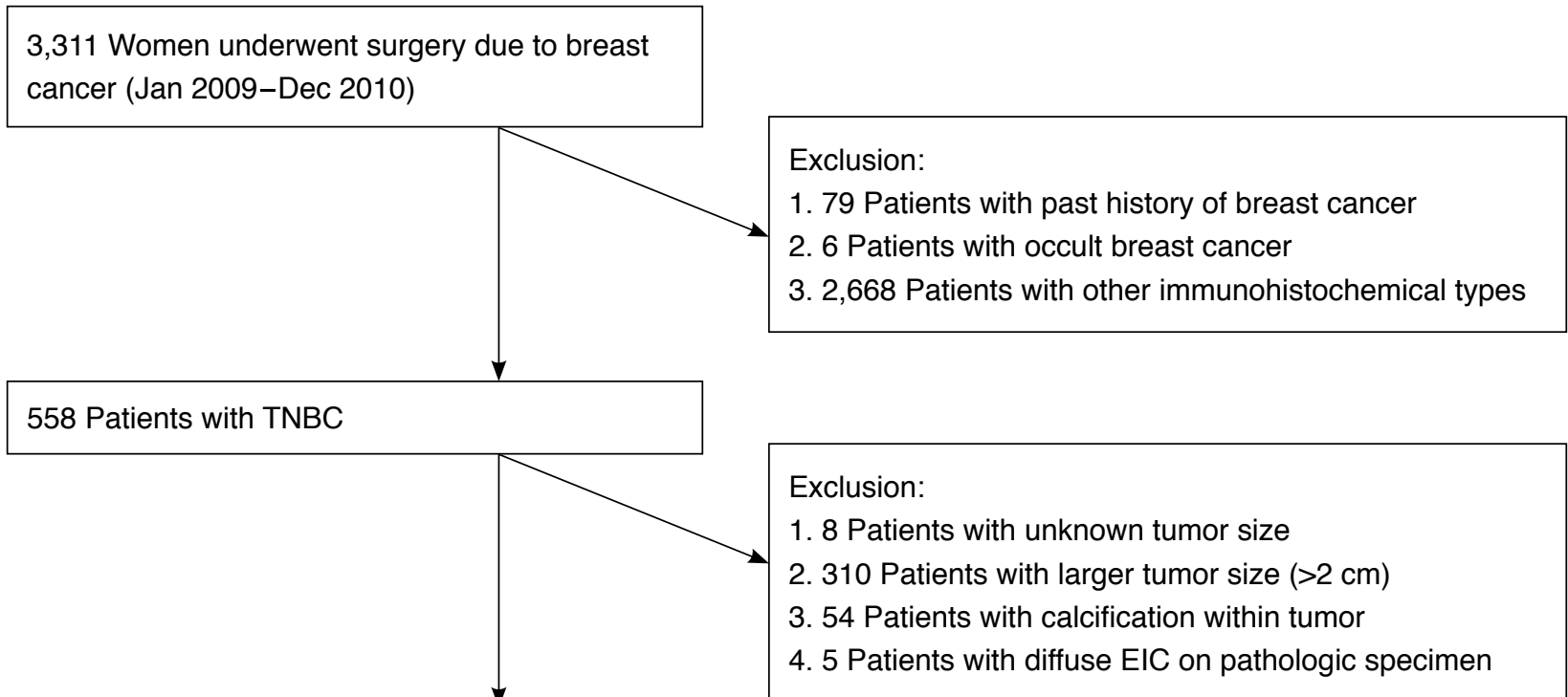

Inclusion:

181 Patients with TNBC ( $\leq 2 \mathrm{~cm}$ in longest diameter)

Fig. 1. Inclusion criteria. TNBC, triple-negative breast cancer; EIC, extensive intraductal component. 
equipment with a 14-16 MHz linear array transducer (IU 22, Philips Medical Systems, Bothell, WA, USA).

Two radiologists (J.H.C., with 17 years of experience in breast radiology, and G.Y.Y., with 2 years of experience in breast radiology) who were blinded to the clinical information interpreted the US findings and arrived at a consensus. The size, shape (oval, round, or irregular), orientation (parallel or nonparallel), margin (circumscribed or noncircumscribed: indistinct, angular, microlobulated, or spiculated), echotexture (anechoic, hyperechoic, isoechoic, hypoechoic, complex, or heterogeneous echo), posterior echo feature (none, enhancement, shadowing, or combined), and associated features (duct changes, architectural distortion, edema, skin thickening, or none) of the lesions were analyzed according to the fifth edition of the Breast Imaging Reporting and Data System (BI-RADS) lexicon [12]. The BI-RADS final assessment categories are defined as follows: category 3, probably benign; category $4 a$, low suspicion for malignancy; category $4 b$, moderate suspicion for malignancy; category 4c, high suspicion for malignancy; and category 5 , highly suggestive of malignancy [12].

Tumor roundness was measured quantitatively using software developed in-house in Microsoft Visual C++ (version 2005, Microsoft, Redmond, WA, USA) and calculated according to the following equation $[13,14]$ :

Tumor roundness $=4 \pi \times A / P^{2}$,

where $A$ is the cross-sectional area (determined using the perimeter method) of the tumor, and $P$ is the measured length of the perimeter of the tumor. The tumor roundness score ranged from 1 to $100 \%$. A perfectly round-shaped tumor would have a roundness score of 100.

\section{Pathology}

The TNBC group underwent breast-conserving surgery $(n=165)$ or modified radical mastectomy $(n=16)$. All resected specimens were histopathologically verified, and the cancer type and tumor characteristics were evaluated. ER-negative, PR-negative, and HER2 negative tumors were classified as TNBC. The levels of ER, PR, and HER2 were routinely determined by immunohistochemistry. The cutoff point for ER- and PR-positive expression was 10\%. HER2 status was graded as $0,1+, 2+$, and $3+$, with $3+$ regarded as positive, and 0 or $1+$ regarded as negative. Tumors with a HER2 status of $2+$ were checked for positivity using fluorescence in situ hybridization.

Diagnosis of the fibroadenomas was histopathologically established in all patients following an US-guided percutaneous core needle biopsy examination. All lesions were finally confirmed as fibroadenoma by follow-up of the lesion for more than 2 years $(n=142)$ or surgical excision $(n=30)$.

\section{Statistical Analysis}

Data analysis was performed using the Student t test or a nonparametric test for continuous variables, and the Pearson chi-square test was used for categorical variables. Univariate and multivariate analyses were performed to identify significant independent factors distinguishing between the groups. P-values of $<0.05$ were considered to indicate a statistically significant difference. Statistical analyses were performed using SPSS ver. 21.0 (IBM Corp., Armonk, NY, USA).

\section{Results}

The mean age at diagnosis was $49.9 \pm 10.3$ years in the TNBC group and $48.3 \pm 9.0$ years in the fibroadenoma group, with no significant difference between the two groups. The median longest lesion dimension was $16 \mathrm{~mm}$ (range, 13 to $18 \mathrm{~mm}$ ) for the TNBCs and 13 $\mathrm{mm}$ (range, 10 to $16 \mathrm{~mm}$ ) for the fibroadenomas. Table 1 shows the sonographic features of the TNBCs and fibroadenomas. Most TNBCs presented with an irregular shape $(66.9 \%, 121$ of 181$)$ than an oval $(22.1 \%, 40$ of 181$)$ or round $(11.1 \%, 20$ of 181$)$ shape. The margin of the TNBCs was mostly noncircumscribed $(91.7 \%, 166$ of $181)$ and only infrequently was it circumscribed (8.3\%, 15 of 181). However, more fibroadenomas showed a circumscribed margin $(51.2 \%, 88$ of 172$)$ than a noncircumscribed margin $(48.8 \%, 84$ of 172$)$. The orientation was mostly parallel in both groups $(84.0 \%$ of TNBCs, 152 of 181 vs. $97.7 \%$ of fibroadenomas, 168 of 172), although a nonparallel orientation was more frequent in the TNBC group $(16.0 \%, 29$ of 181$)$ than in the fibroadenoma group $(2.3 \%$, four of 172). A low median width-to-height ratio (1.5; range, 1.3 to 1.8 in TNBCs vs. 1.9 ; range, 1.6 to 2.3 in fibroadenomas) was also associated with the TNBC group. The echotexture was mostly hypoechoic in both groups (59.1\% of TNBCs, 107 of 181 vs. $54.1 \%$ of fibroadenomas, 93 of 172). Posterior acoustic enhancement presented more commonly in the TNBC group $(65.2 \%, 118$ of 181) than in the fibroadenoma group $(50.0 \%, 86$ of 172$)$, although it was a common feature in both groups. More associated features were evident in the TNBC group $(25.4 \%, 46$ of 181$)$ than in the fibroadenoma group (2.9\%, five of 172). Most TNBCs were assigned to BI-RADS category $4(65.2 \%, 118$ of 181$)$ or $5(28.2 \%, 51$ of 181), while most fibroadenomas belonged to BI-RADS category $3(55.8 \%, 96$ of 172). TNBCs demonstrated greater mean tumor roundness than fibroadenomas $(60 \% \pm 12 \%$ vs. $53 \% \pm 13 \%$, respectively). All these findings were significantly different between TNBCs and fibroadenoma.

In a subgroup analysis by size, smaller TNBCs, measuring less than or equal to $1 \mathrm{~cm}$, consistently presented with an irregular shape, a higher percentage of nonparallel orientation, a lower 
width-to-height ratio, a BI-RADS final assessment category of 4 or 5 , and a greater mean tumor roundness than fibroadenomas. These differences were statistically significant. However, the margin, posterior echo features, and associated features showed no significant differences between these two groups.

Twelve TNBC cases were assessed as BI-RADS category 3 (Fig.
2). However, in all 12 cases, US-guided core needle biopsy was performed due to palpability, pain, increasing size, the patient's anxiety, and metastatic lymphadenopathy.

Eight fibroadenomas had high BI-RADS final assessment categories: category $4 \mathrm{~b}$ (two of eight), 4c (one of eight), and 5 (five of eight). Of these, six lesions had an irregular shape, and all these

Table 1. Sonographic features of TNBC and fibroadenoma according to size

\begin{tabular}{|c|c|c|c|c|c|c|c|c|c|}
\hline \multirow[b]{2}{*}{ Factor } & \multirow{2}{*}{ TNBC $(n=181)$} & \multirow{2}{*}{$\begin{array}{l}\text { Fibroadenoma } \\
\qquad(n=172)\end{array}$} & \multirow{2}{*}{ P-value } & \multicolumn{3}{|c|}{ Lesion size $\leq 1 \mathrm{~cm}$} & \multicolumn{3}{|c|}{$1 \mathrm{~cm}<$ lesion size $\leq 2 \mathrm{~cm}$} \\
\hline & & & & $\begin{array}{c}\text { TNBC } \\
(n=24)\end{array}$ & $\begin{array}{l}\text { Fibroadenoma } \\
\quad(n=57)\end{array}$ & P-value ${ }^{a)}$ & $\begin{array}{c}\text { TNBC } \\
(n=157)\end{array}$ & $\begin{array}{l}\text { Fibroadenoma } \\
\quad(n=115)\end{array}$ & P-value ${ }^{a)}$ \\
\hline Size $(\mathrm{mm})$ & $\begin{array}{c}16.0 \\
(13.0-18.0)\end{array}$ & $\begin{array}{c}13.0 \\
(10.0-16.0)\end{array}$ & $<0.001$ & $\begin{array}{c}8.0 \\
(7.0-9.5)\end{array}$ & $\begin{array}{c}9.0 \\
(8.0-10.0)\end{array}$ & 0.144 & $\begin{array}{c}17.0 \\
(15.0-18.0)\end{array}$ & $\begin{array}{c}15.0 \\
(13.0-17.5)\end{array}$ & 0.001 \\
\hline Shape & & & $<0.001$ & & & 0.001 & & $<0.001$ & \\
\hline Oval or round & $60(33.2)$ & $132(76.7)$ & & $14(58.3)$ & $44(77.2)$ & & $46(29.3)$ & $88(76.5)$ & \\
\hline Margin & & & $<0.001$ & & & 0.209 & & & $<0.001$ \\
\hline Circumscribed & $15(8.3)$ & $88(51.2)$ & & $6(25.0)$ & $27(47.4)$ & & $9(5.7)$ & $61(53.0)$ & \\
\hline Noncircumscribed & $166(91.7)$ & $84(48.8)$ & & $18(75.0)$ & $30(52.6)$ & & $148(94.3)$ & $54(47.0)$ & \\
\hline Orientation & & & $<0.001$ & & & 0.021 & & & $<0.001$ \\
\hline Parallel & $152(84.0)$ & $168(97.7)$ & & $17(70.8)$ & $53(93.0)$ & & $135(86.0)$ & $115(100)$ & \\
\hline Echotexture & & & $<0.001$ & & & 0.061 & & & $<0.001$ \\
\hline Hyperechoic & $2(1.1)$ & 0 & & 0 & 0 & & $2(1.3)$ & 0 & \\
\hline Isoechoic & $10(5.5)$ & $58(33.7)$ & & $5(20.8)$ & $25(43.9)$ & & $5(3.2)$ & $33(28.7)$ & \\
\hline Complex & $11(6.1)$ & $1(0.6)$ & & 0 & $1(1.8)$ & & $11(7.0)$ & 0 & \\
\hline Hypoechoic & $107(59.1)$ & $93(54.1)$ & & $16(66.7)$ & $30(52.6)$ & & $91(58.0)$ & $63(54.8)$ & \\
\hline Heterogeneous & $51(28.2)$ & $20(11.6)$ & & $3(12.5)$ & $1(1.8)$ & & $48(30.6)$ & $19(16.5)$ & \\
\hline Posterior echo features & & & 0.001 & & & 0.875 & & & $<0.001$ \\
\hline None & $53(29.3)$ & $84(48.8)$ & & $14(58.3)$ & $36(63.2)$ & & $39(24.8)$ & $48(41.7)$ & \\
\hline Enhancement & $118(65.2)$ & $86(50.0)$ & & $10(41.7)$ & $21(36.8)$ & & $108(68.8)$ & $65(56.5)$ & \\
\hline Category 3 & $12(6.6)$ & $96(55.8)$ & & $5(20.8)$ & $38(66.7)$ & & $7(4.5)$ & $52(45.2)$ & \\
\hline Category 4a & $48(26.5)$ & $68(39.5)$ & & $13(54.2)$ & $16(28.1)$ & & $35(22.3)$ & $2(1.7)$ & \\
\hline Category 4b & $37(20.4)$ & $2(1.2)$ & & $4(16.7)$ & 0 & & $33(21.0)$ & 0 & \\
\hline Category $4 c$ & $33(18.2)$ & $1(0.6)$ & & 0 & $1(1.8)$ & & $33(21.0)$ & $58(50.4)$ & \\
\hline Category 5 & $51(28.2)$ & $5(2.9)$ & & $2(8.3)$ & $2(3.5)$ & & 49 (31.2) & $3(2.6)$ & \\
\hline Tumor roundness & $60 \pm 12$ & $53 \pm 13$ & $<0.001$ & $65 \pm 13$ & $59 \pm 13$ & 0.037 & $60 \pm 12$ & $51 \pm 12$ & $<0.001$ \\
\hline
\end{tabular}

Values are presented as median (first quartile-third quartile) or number (\%).

TNBC, triple-negative breast cancer; BI-RADS, Breast Imaging Reporting and Data System.

${ }^{a)} \mathrm{A}$ P-value less than 0.05 was considered to indicate a statistically significant difference. 


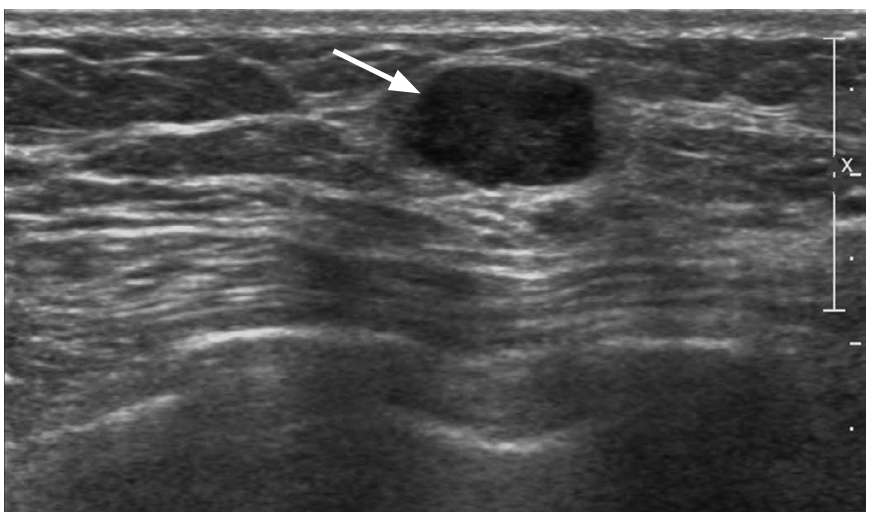

Fig. 2. A 68-year-old woman with a palpable mass in the left breast. Ultrasonography (US) shows a circumscribed, oval-shaped, hypoechoic mass (arrow) with posterior acoustic enhancement in the left breast. US-guided biopsy confirmed triple-negative breast cancer.

lesions showed a noncircumscribed margin, defined as indistinct (two of eight) or spiculated (six of eight), with a hypoechoic (five of eight) or heterogeneous (three of eight) echotexture. Other features, such as a parallel orientation and the absence of associated features, were more closely related to benign findings in these lesions. Among these eight patients, six underwent surgical excision and were diagnosed with fibroadenoma. The other two patients did not wish to undergo surgery, and finally diagnosed with fibroadenoma by a long-term follow-up of more than 2 years.

The results of the univariate analysis of the sonographic features of the TNBC and fibroadenoma groups are presented in Table 2. Multiple factors were found to be significantly associated with TNBCs, including larger tumor size (odds ratio $[O R], 1.15 ; \mathrm{P}<0.001$ ), irregular shape (OR, 6.66; $P<0.001)$, a noncircumscribed margin (OR of a circumscribed margin, $0.09 ; P<0.001)$, a nonparallel orientation (OR, 8.01; $P<0.001)$, a lower width-to-height ratio $(O R, 0.19$; $P<0.001)$, posterior acoustic enhancement $(O R, 2.18 ; P<0.001)$, combined associated features (OR, 11.38; $P<0.001)$, a BI-RADS final assessment category 4 (OR of $4 b, 26.21 ; P \leq 0.001 ; O R$ of $4 c, 46.75$; $P<0.001)$ or $5(O R, 14.45 ; P<0.001)$, and greater tumor roundness $(O R, 103.16 ; P<0.001)$. In the univariate analysis of the size-based subgroups, the same results were found, except for age $(P=0.099)$, orientation (not calculable) and hypoehoic echotexture $(P=0.077)$. However, fewer factors were significantly associated with TNBCS in the smaller TNBC and fibroadenoma groups: irregular shape $(O R, 2.42 ; P=0.090)$, nonparallel orientation ( $O R, 5.46 ; P=0.013)$, lower width-to-height ratio (OR, 0.23; $\mathrm{P}=0.007)$, and greater tumor roundness ( $O R, 70.96 ; \mathrm{P}=0.042$ ).

The multivariate analysis showed that older patient age (OR, 1.06; $P=0.003)$, irregular shape $(O R, 2.96 ; P=0.011)$, nonparallel orientation ( $O R, 5.25 ; P=0.022)$, posterior acoustic enhancement (OR, 4.49; $P<0.001)$, a BI-RADS final assessment category of 4 (OR of $4 b, 21.28 ; P<0.001 ; O R$ of $4 c, 41.61 ; P=0.001)$ or $5(O R, 8.66$; $P=0.001)$, and greater tumor roundness $(O R, 71.62 ; P=0.003)$ were significant independent factors associated with TNBCs (Table 2).

In the multivariate analysis of the two subgroups defined according to size, only BI-RADS final assessment category 3 (OR, $0.09 ; \mathrm{P}<0.001$ ) was a significant independent factor associated with smaller fibroadenomas. In contrast, older patient age (OR, 1.06; $P=0.017)$, irregular shape $(O R, 3.77 ; P=0.023)$, a noncircumscribed margin (OR of circumscribed margin, $0.22 ; P=0.031$ ), posterior acoustic enhancement $(O R, 11.19, P<0.001)$, a BI-RADS final assessment category of 4 (OR of $4 b, 14.86 ; P=0.003)$ or 5 $(O R, 46.47 ; P<0.001)$, and greater tumor roundness (OR, 230.27; $\mathrm{P}=0.002$ ) were significantly associated with larger TNBCs.

\section{Discussion}

In our study, most TNBCs and fibroadenomas showed a hypoechoic echotexture and posterior acoustic enhancement. Prior studies have reported that the distinctive sonographic findings of TNBC include a circumscribed margin and a hypoechoic echotexture with associated posterior acoustic enhancement $[3,15-17]$. These findings of TNBCs can be confused with those of benign tumors, and we are not aware of an US imaging study comparing such findings between these two groups, especially in tumors of a small size. Moon et al. [18] demonstrated that a computer-aided diagnosis (CAD) system based on texture features might be useful for discriminating between TNBCs and benign fibroadenomas in US, but it is not practically feasible to utilize such a CAD system for every examination. In our study, TNBCs showed more suspicious sonographic features than fibroadenomas, including an irregular shape, noncircumscribed margin, nonparallel orientation, low widthto-height ratio, and associated features. When we subdivided the TNBCs and fibroadenomas according to size (less than or equal to $1 \mathrm{~cm}$ vs. greater than $1 \mathrm{~cm}$ and less than or equal to $2 \mathrm{~cm}$ ), larger TNBCs showed the same malignant-looking features. In the smaller TNBCs, the margins of the lesion and the presence of associated features did not show a significant difference from the smaller fibroadenomas. The differentiation of noncircumscribed margins, including microlobulated, indistinct, angular, and speculated margins, can be difficult in small lesions [19]. However, other sonographic findings, including irregular shape, nonparallel orientation, and a low width-to-height ratio were still common in the smaller TNBCs. These findings might be helpful for differentiating small TNBCs from small benign tumors.

Among the $12 \mathrm{BI}$-RADS category 3 lesions in the TNBC group, 
most patients ( $n=8,66.7 \%)$ presented with symptoms, such as palpation (seven of eight), and palpation with pain (one of eight). All symptomatic patients were more than 40 years old. Patterson et al. [20] reported that the overall cancer rate was $1.6 \%$ in the solid palpable masses assessed as BI-RADS category 3 or $4 a$, and that incidence increased with age [20]. Although these lesions showed characteristically benign sonographic findings, palpable masses in women over 40 years old should be considered for pathologic confirmation, because it is difficult to differentiate between malignant and benign lesions in this patient population. A growing mass and secondary signs such as lymphadenopathy are also significant factors prompting biopsy.

Table 2. Univariate and multivariate analysis of sonographic features in the TNBC and fibroadenoma groups

\begin{tabular}{|c|c|c|c|c|}
\hline \multirow{2}{*}{ Factor } & \multicolumn{2}{|c|}{ Univariate } & \multicolumn{2}{|c|}{ Multivariate } \\
\hline & $\mathrm{OR}(95 \% \mathrm{Cl})$ & P-value ${ }^{\text {a) }}$ & OR $(95 \% \mathrm{Cl})$ & P-value ${ }^{a)}$ \\
\hline Age (yr) & $1.02(1.00-1.04)$ & 0.131 & $1.06(1.02-1.10)$ & 0.003 \\
\hline Size (mm) & $1.15(1.09-1.22)$ & $<0.001$ & - & - \\
\hline \multicolumn{5}{|l|}{ Shape } \\
\hline Oval or round & 1 (ref) & & 1 (ref) & \\
\hline Irregular & $6.66(4.19-10.75)$ & $<0.001$ & $2.96(1.30-6.93)$ & 0.011 \\
\hline \multicolumn{5}{|l|}{ Margin } \\
\hline Noncircumscribed & 1 (ref) & & - & \\
\hline Circumscribed & $0.09(0.05-0.15)$ & $<0.001$ & - & - \\
\hline \multicolumn{5}{|l|}{ Orientation } \\
\hline Parallel & 1 (ref) & & 1 (ref) & \\
\hline Nonparallel & $8.01(3.07-27.48)$ & $<0.001$ & $5.25(1.35-23.90)$ & 0.022 \\
\hline Width-to-height ratio & $0.19(0.11-0.30)$ & $<0.001$ & - & - \\
\hline \multicolumn{5}{|l|}{ Echotexture } \\
\hline Heterogeneous & 1 (ref) & & 1 (ref) & \\
\hline Hyperechoic & $\ln f^{b)}(0-\operatorname{lnf})$ & & $\operatorname{lnf}(0-\operatorname{lnf})$ & \\
\hline Isoechoic & $0.07(0.03-0.15)$ & $<0.001$ & $0.31(0.09-1.04)$ & 0.063 \\
\hline Complex & $4.31(0.76-81.42)$ & 0.175 & $17.87(2.03-412.46)$ & 0.022 \\
\hline Hypoechoic & $0.45(0.25-0.80)$ & 0.008 & $1.10(0.045-2.73)$ & 0.841 \\
\hline \multicolumn{5}{|l|}{ Posterior echo features } \\
\hline None & 1 (ref) & & 1 (ref) & \\
\hline Enhancement & $2.18(1.40-3.40)$ & $<0.001$ & $4.49(2.07-10.40)$ & $<0.001$ \\
\hline Shadowing & $7.93(1.23-154.06)$ & 0.062 & $0.90(0.07-24.07)$ & 0.937 \\
\hline Combined & $7.93(1.23-154.06)$ & 0.062 & $0.33(0.012-11.22)$ & 0.482 \\
\hline \multicolumn{5}{|l|}{ Associated features } \\
\hline None & 1 (ref) & & 1 (ref) & \\
\hline Present & $11.38(4.82-33.53)$ & $<0.001$ & $4.47(1.04-22.78)$ & 0.055 \\
\hline \multicolumn{5}{|l|}{ BI-RADS category } \\
\hline 3 & $0.18(0.08-0.35)$ & $<0.001$ & $0.29(0.11-0.72)$ & 0.009 \\
\hline $4 a$ & 1 (ref) & & 1 (ref) & \\
\hline $4 b$ & $26.21(7.52-166.04)$ & $<0.001$ & $21.28(5.28-146.61)$ & $<0.001$ \\
\hline $4 c$ & $46.75(9.55-845.49)$ & $<0.001$ & $41.61(6.40-871.04)$ & 0.001 \\
\hline 5 & $14.45(5.84-43.92)$ & $<0.001$ & $8.66(2.58-36.75)$ & 0.001 \\
\hline Tumor roundness & $103.16(17.66-661.62)$ & $<0.001$ & $71.62(4.61-1,319.18)$ & 0.003 \\
\hline
\end{tabular}

TNBC, triple-negative breast cancer; OR, odds ratio; Cl, confidence interval; ref, reference; BI-RADS, Breast Imaging Reporting and Data System.

${ }^{a)} \mathrm{A}$ P-value less than 0.05 was considered to indicate a statistically significant difference. ${ }^{\text {b) }}$ The value could not be calculated as there were no hyperechoic lesions in the fibroadenoma group. 
Fibroadenomas (eight of 172) in the high BI-RADS final assessment category group had an irregular shape (six of eight) with a hypoechoic echotexture (five of eight), and all lesions (eight) revealed a noncircumscribed margin. Such lesions on breast US are usually considered to be suspicious [12]. However, Taskin et al. [21] demonstrated that among pathologically confirmed lesions $(n=172)$ with one or more suspicious sonographic finding, including an irregular shape, noncircumscribed margin, hypoechoic or heterogeneous echotexture, posterior acoustic shadowing, and the presence of microcalcifications, there were 66 fibroadenomas (38\%). Careful US examinations and US-guided core needle biopsy can help differentiate such lesions from malignancies.

Associated features are defined as the effects of a mass on its surroundings [12]. We found more associated features in TNBCS than in fibroadenomas, with edema and skin thickening occurring only in the TNBC group. Therefore, associated features, especially in the small tumor size-range corresponding to the T1 stage (measuring less than or equal to $2 \mathrm{~cm}$ ), could be helpful for differentiating between malignant and benign lesions. However, no associated features were present in smaller TNBCs, which indicates a limitation in the degree to which this parameter can be used to differentiate very small tumors.

In this study, the TNBC group, especially the smaller TNBC group, demonstrated more lesions with a nonparallel orientation than the fibroadenoma group, and a low median width-to-height ratio was also more strongly associated with the TNBC group. These findings can be explained by the small TNBC tumor size at presentation. Traditionally, a taller-than-wide shape is characteristic of small carcinomas [22]. Tumor roundness was slightly greater in the TNBC group than in the fibroadenoma group, with most fibroadenomas having an oval shape.

The multivariate analysis showed that older patient age, irregular shape, nonparallel orientation, posterior acoustic enhancement, a BI-RADS category of 4 or 5 , and greater tumor roundness were significant independent factors associated with TNBCs, even though there was no significant independent factor predictive of smaller TNBCs. These findings are consistent with a likelihood of malignancy $[22,23]$.

This study has several limitations. First, our analysis was conducted at a single tertiary referral center and was of a retrospective nature. Second, color Doppler or elastography studies were not routinely performed, and these can be helpful for diagnosis. Third, we did not include the findings of other imaging modalities such as mammography or magnetic resonance imaging. In the TNBC group, 107 patients presented with dense breasts on mammography, in whom 36 lesions were not visible, while a preoperative mammogram was not available for 13 patients. Patients diagnosed with fibroadenoma ( $n=54)$ did not undergo routine mammography. For these reasons, we did not include a review and analysis of mammographic features. No patients with fibroadenoma underwent magnetic resonance imaging.

In conclusion, the sonographic features and tumor roundness of small TNBCs showed some differences from the corresponding features of fibroadenomas. These features may help differentiate between small TNBCs and fibroadenomas.

ORCID: Ga Young Yoon: http://orcid.org/0000-0003-0933-1570; Joo Hee Cha: http:// orcid.org/0000-0002-1446-8195; Hak Hee Kim: http://orcid.org/0000-0002-29569212; Hee Jung Shin: http://orcid.org/0000-0002-3398-1074; Eun Young Chae: http://orcid.org/0000-0002-3478-6721; Woo Jung Choi: http://orcid.org/0000-00031341-6470

\section{Conflict of Interest}

No potential conflict of interest relevant to this article was reported.

\section{References}

1. Foulkes WD, Smith IE, Reis-Filho JS. Triple-negative breast cancer. N Engl J Med 2010;363:1938-1948.

2. Kriege $M$, Brekelmans $C T$, Boetes $C$, Besnard PE, Zonderland $H M$, Obdeijn IM, et al. Efficacy of MRI and mammography for breast-cancer screening in women with a familial or genetic predisposition. N Engl J Med 2004;351:427-437.

3. Dogan $B E$, Turnbull LW. Imaging of triple-negative breast cancer. Ann Oncol 2012;23 Suppl 6:vi23-vi29.

4. Yang WT, Dryden M, Broglio K, Gilcrease M, Dawood S, Dempsey PJ, et al. Mammographic features of triple receptor-negative primary breast cancers in young premenopausal women. Breast Cancer Res Treat 2008;111:405-410.

5. Wang Y, Ikeda DM, Narasimhan B, Longacre TA, Bleicher RJ, Pal S, et al. Estrogen receptor-negative invasive breast cancer: imaging features of tumors with and without human epidermal growth factor receptor type 2 overexpression. Radiology 2008;246:367375.

6. Dogan BE, Gonzalez-Angulo AM, Gilcrease M, Dryden MJ, Yang WT. Multimodality imaging of triple receptor-negative tumors with mammography, ultrasound, and MRI. AJR Am J Roentgenol 2010;194:1160-1166.

7. Bae MS, Moon WK, Chang JM, Koo HR, Kim WH, Cho N, et al. Breast cancer detected with screening US: reasons for nondetection at mammography. Radiology 2014;270:369-377.

8. Kojima Y, Tsunoda H. Mammography and ultrasound features of triple-negative breast cancer. Breast Cancer 2011;18:146-151.

9. de Ruijter TC, Veeck J, de Hoon JP, van Engeland M, Tjan-Heijnen VC. Characteristics of triple-negative breast cancer. J Cancer Res Clin Oncol 2011;137:183-192. 
10. Dent R, Trudeau M, Pritchard KI, Hanna WM, Kahn HK, Sawka CA, et al. Triple-negative breast cancer: clinical features and patterns of recurrence. Clin Cancer Res 2007;13(15 Pt 1):4429-4434.

11. Ryu EB, Chang JM, Seo M, Kim SA, Lim JH, Moon WK. Tumour volume doubling time of molecular breast cancer subtypes assessed by serial breast ultrasound. Eur Radiol 2014;24:2227-2235.

12. Mendelson EB, Bohm-Velez M, Berg WA, Whitman GJ, Feldman MI, Madjar $\mathrm{H}$, et al. ACR BI-RADS ultrasound. In: D'Orsi CJ, Sickles EA, Mendelson EB, Morris EA, eds. ACR BI-RADS Atlas, Breast Imaging Reporting and Data System. 5th ed. Reston, VA: American College of Radiology, 2013;1-173.

13. Tseng HS, Wu HK, Chen ST, Kuo SJ, Huang YL, Chen DR. Speckle reduction imaging of breast ultrasound does not improve the diagnostic performance of morphology-based CAD System. J Clin Ultrasound 2012;40:1-6.

14. Bae MS, Seo M, Kim KG, Park IA, Moon WK. Quantitative MRI morphology of invasive breast cancer: correlation with immunohistochemical biomarkers and subtypes. Acta Radiol 2015;56:269-275.

15. Li Z, Tian J, Wang X, Wang Y, Wang Z, Zhang L, et al. Differences in multi-modal ultrasound imaging between triple negative and nontriple negative breast cancer. Ultrasound Med Biol 2016;42:882890.

16. Du HY, Lin BR, Huang DP. Ultrasonographic findings of triple- negative breast cancer. Int J Clin Exp Med 2015;8:10040-10043.

17. Ko ES, Lee BH, Kim HA, Noh WC, Kim MS, Lee SA. Triple-negative breast cancer: correlation between imaging and pathological findings. Eur Radiol 2010;20:1111-1117.

18. Moon WK, Huang YS, Lo CM, Huang CS, Bae MS, Kim WH, et al. Computer-aided diagnosis for distinguishing between triplenegative breast cancer and fibroadenomas based on ultrasound texture features. Med Phys 2015;42:3024-3035.

19. Hong AS, Rosen EL, Soo MS, Baker JA. BI-RADS for sonography: positive and negative predictive values of sonographic features. AJR Am J Roentgenol 2005;184:1260-1265.

20. Patterson SK, Neal CH, Jeffries DO, Joe A, Klein K, Bailey J, et al. Outcomes of solid palpable masses assessed as BI-RADS 3 or 4A: a retrospective review. Breast Cancer Res Treat 2014;147:311-316.

21. Taskin F, Koseoglu K, Ozbas S, Erkus M, Karaman C. Sonographic features of histopathologically benign solid breast lesions that have been classified as BI-RADS 4 on sonography. J Clin Ultrasound 2012;40:261-265.

22. Stavros AT, Thickman D, Rapp CL, Dennis MA, Parker SH, Sisney GA. Solid breast nodules: use of sonography to distinguish between benign and malignant lesions. Radiology 1995;196:123-134.

23. Gokhale S. Ultrasound characterization of breast masses. Indian J Radiol Imaging 2009;19:242-247. 